\title{
Energy Efficiency of LVDC Supplies Including PV Sources
}

\author{
Anis Ammous ${ }^{1,2}$, Abdulrahman Alahdal ${ }^{1}$, Kaiçar Ammous ${ }^{2}$ \\ ${ }^{1}$ Department of Electrical Engineering, College of Engineering and Islamic Architecture, Umm Al- \\ Qura University, KSA \\ ${ }^{2}$ Department of Electrical Engineering, National School of Engineers of Sfax, University of Sfax, \\ Tunisia
}

Received: March 3, 2021. Revised: March 29, 2021. Accepted: April 2, 2021. Published: April 6, 2021.

\begin{abstract}
The Low Voltage Direct Current (LVDC) system concept has been growing in the recent times due to its characteristics and advantages like renewable energy source compatibility, more straightforward integration with storage utilities through power electronic converters and distributed loads. This paper presents the energy efficiency performances of a proposed LVDC supply concept and others classical PV chains architectures. A PV source was considered in the studied nanogrids. The notion of Relative Saved Energy (RSE) was introduced to compare the studied PV systems energy performances. The obtained results revealed that the employment of the LVDC chain supply concept is very interesting and the use of DC loads as an alternative to AC loads, when a PV power is generated locally, is more efficient. The installed PV power source in the building should be well sized regarding to the consumed power in order to register a high system RSE.
\end{abstract}

\section{INTRODUCTION}

The photovoltaic electricity was primarily established for standalone applications deprived of any connection to a power grid. Such was the case of satellites or isolated habitations. Currently, PV's are found in many power applications like personal calculators, watches and other objects of daily use, they can supply many individual DC loads without difficulty. Due to the evolution of photovoltaic systems connected to the grid, the PV has considerably exploited as a solution to produce electricity.

The main objective of this paper is to investigate the energy efficiency performance of a proposed Low-Voltage Direct Current (LVDC) PV system regarding to a classical LVDC architecture and classical PV systems using AC loads. All the studied PV chains are on-grid ones and are supposed supplying offices.
In general, electric energy consumption in office applications and housing is achieved by using the alternative current plugs even for Grid Tie PV panel systems. In this case the use of AC's can increase system losses especially when DC current is used at the load levels.

LVDC systems have been gaining more interest during the past few years both in academia and industry. LVDC systems offer many advantages covering higher energy efficiency and easier integration of modern energy resources in comparison to conventional AC systems. Multiple factors affecting the reliability performance and power quality of the electricity supply permit the use of DC systems instead of AC systems. Direct use of DC power would reduce many power conversion losses by exploiting self-consumption of the energy produced on site and decreasing imports of electricity from the grid. DC loads used in households and office buildings, also operate on DC, heating/cooling systems and larger equipment used in industry such as variable frequency drives have also adopted DC motors. Direct current power systems are essentially more efficient than their AC counterparts; since in DC systems do not suffer from skin effect or reactive power [1], [2], [3], [9]. A literature research has exposed the study of the first system analysis explored the use of very low voltage $(<120 \mathrm{~V})$ in small-size systems, particularly residential dwellings [6].

Subsequently, Lasseter R.H proposed the concept of the DC Microgrid as a low voltage distribution network. This concept was projected as the future low voltage distribution systems which were facing revolutionary variations at the time due to emanation of distributed generation and market liberalization. The basic idea behind this concept is to combine micro sources and loads into one entity which could be interpreted as a single dispatch-able load that could respond in short time to meet the transmission system needs [7].

For many years, The LVDC system has been developed for specific applications like aerospace, automotive and marine [4], [5], [8]. Literature review reveals that over the last decades, LVDC systems are growing rapidly for industrial applications, essentially in the telecommunication industry, ships and buildings. Adopting Direct Current in data centers 
improve efficiency, decrease capital cost, increase reliability and boost power quality [12]. In data centers, LVDC architectures have been widely studied. Various leader projects have been installed in Europe, the United States, Oceania and Asia. From these projects it was registered that the profit of DC in data-centers are about $10 \%$ to $30 \%$ reduction in energy consumption, about $15 \%$ lower capital costs, simpler design, potential increase in reliability, less physical area requirements, a smaller carbon footprint and less cooling demand [10], [11].

The most significant challenge that DC distribution systems face today is the lack of standardization inducing varied architectures and operations of DC distribution systems [13], [16].

The work presented in [15] was accomplished in many various locations through the country, with different types of system topologies. Further, distribution topologies were carried out for both two cases with and without energy storage.

Studies conducted in [15], [16] aim to accomplish $25-30 \%$ of energy savings. The environment conditioning loads are very significant part in Buildings and should be explored in further studies.

The authors in [17] reported that the majority of electricity used in on office building passes through power converters enclosing further conversions. Average conversion efficiency is closed $68 \%$. When using high quality electronics, only a $10 \%$ loss from each stage of conversion is considered as generous number.

Hence, the losses are multiplicative and not additive. An uninterruptable power supply (UPS) use the battery to keep supported loads up. For storage in a battery, power is converted from AC power to DC. For the server plug, DC/AC conversion is crucial. The processors use the DC power achieved by the server so multi-stage conversion structures $(\mathrm{AC} / \mathrm{DC} / \mathrm{AC} / \mathrm{DC})$ are used in this case.

The DC power is directly produced from residential solar panels and inverter is commonly added to supply AC loads.

Despite that the multi-stage conversion is basic to extract power from the solar panel into the server; losses resulting from these conversions are expected to be between $10 \%$ and $25 \%$.

Through review of the available literature [1], [9], [13], [14], local DC grids are a promising option for buildings to link natural DC power sources such as photovoltaic power systems with DC loads like lighting applications and data centers [10][13].

A. AMMOUS et al. [21] reported that DC microgrids are alternatives promising to conventional $\mathrm{AC}$ distribution networks especially for the integration of renewable energies. They allow, for example, to reduce consumption energy of
$25 \%$ when supplying buildings directly from sectors and by photovoltaic panels.

The majority works on DC distribution grids assume that converters are installed at each household, which connect the local DC or AC nanogrids [18],[19]. In case of distributed energy resources, nanogrids in buildings could be functioned separately from the main grid in islanding mode [19] and typical low voltage subsystems like $48 \mathrm{~V}, 24 \mathrm{~V}$, or $12 \mathrm{~V}$ can be applied [20]. They could, for example, be used for low power LED lighting or for connecting loads by USB Type-C connector and USB Power Delivery.

In the first part of the paper, we focused our study on the state of the art related to the use of the LVDC supply concept and the proposition of an on-grid LVDC PV chain. The disadvantage of the use of classical on-Grid PV systems and of using AC plugs to supply electric DC loads are shown. The used average model of power converters is then presented in the second part. This model allows the evaluation of the different converters efficiencies in the studied PV chains. The last part of the paper treats the energy efficiency performances of the proposed LVDC system compared to others classical ones. For this purpose, offices loads are considered and Jeddah location (in KSA) was chosen in our study.

\section{THE PROPOSED LVDC PV SYSTEM.}

Electronic appliances, such as computers, gaming consoles, printers, economic or LED lights, televisions and so on need DC supplies. Additional AC to DC converters are needed in such equipment.

Figure1 shows one of classical chain used to connect PV panels to the low voltage grid with a transformerless solution. The DC/DC converter, Converter \#1, allows the extraction of the maximum power from the PV panels when climatic conditions changes. The Maximum Power Point Tracking (MPPT) algorithm is used to act on this DC/DC converter control.

The DC/AC converter, Converter \#2, transfers the $\mathrm{PV}$ generated power to the grid and ensures the regulation of the DC voltage value $(400 \mathrm{~V})$ of the inverter input. This $\mathrm{DC}$ value is mainly used value for single phase PV systems allowing to obtain easily the standard $230 \mathrm{~V}$ AC. The injected current to the grid has a quasi-sinusoidal waveform. 


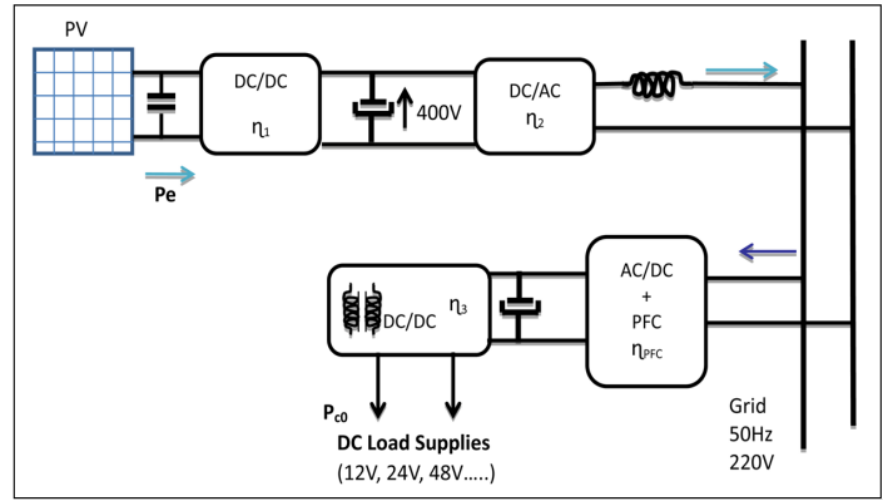

Figure1. Classical configuration (syst1) of the On-Grid PV system and DC load powered from AC sockets.

A main used LVDC photovoltaic architecture is shown in figure 2. This system involve direct current chain form PV to load. The regulated DC bus $(400 \mathrm{~V})$ was used for this purpose and a DC/DC converter $\left(\eta_{3}\right)$ adapts LVDC loads supplies to this DC bus.

The efficiency of each PV conversion chain depends on different considerations like the type of used power semiconductor devices and the magnitude of the transferred power.

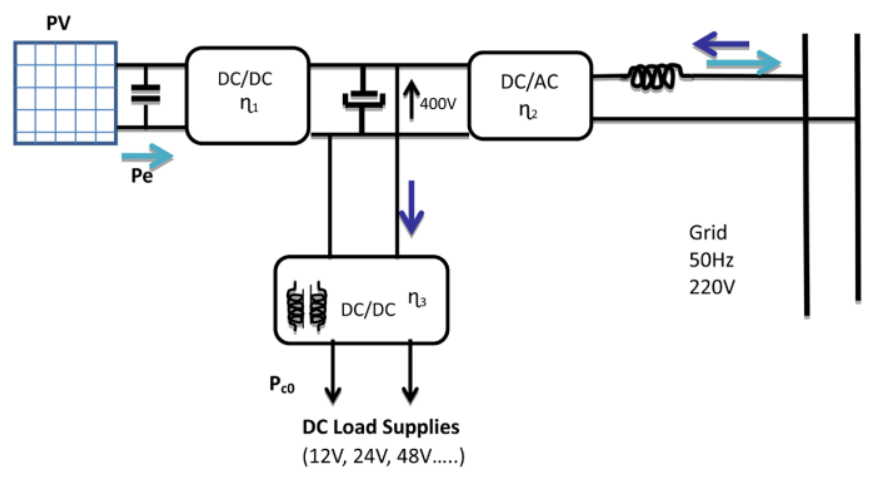

Figure 2. Possible LVDC classical architecture (syst2)

Following we will present the proposed new PV architecture for DC loads supplies and the developed average model of power converters. The proposed LVDC PV chain uses the DC bus available directly after the PV panels. This bus is not regulated but it's value varies in a given range depending on PV panels associations (parallel/series) and open circuit voltage across each panel. The regulation of the DC voltages supplying loads are regulated by DC/DC converters (in general Buck ones). The proposed architecture is the one shown in figure 3. The $\mathrm{DC} / \mathrm{DC}$ converter connecting the $\mathrm{PV}$ panels to the inverter become a reversible DC/DC converter (BuckBoost). The last converter allows the transfer of power from PV panels to the inverter when the generated power is higher than the consumed power. This reversible converter works as a
Buck converter in the case when the consumed power is higher than the PV generated one.

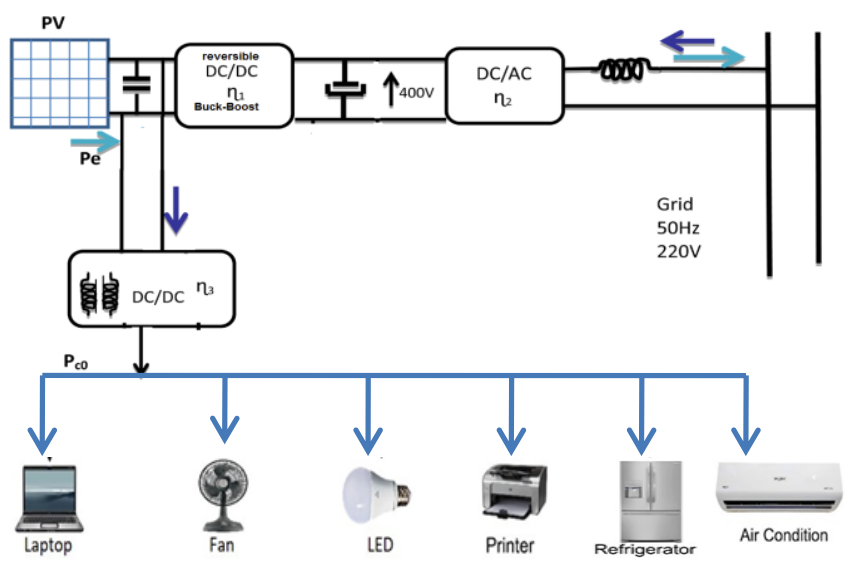

Figure 3. Proposed LVDC architecture (syst3).

\section{POWER CONVERTERS MODELS.}

Modeling is required to analize the dynamic behavior of a power converter in several applications. Since both accuracy and simulation rapidity are essential particularly for long time simulations and for complicated circuits, the averaging method is the widely used technique for complex power electronics systems. Based on the classical averaged model, the converter is considered to be a linear system using ideal switches, however the non-linear averaged model is established on semiconductor device models including static and dynamic characteristics of the switches. Figure 4(a) shows the considered inverter leg with two active switches (IGBTs or MOSFETs) directly controlled by external control signals and two passive switches (DIODEs). In Figure 4(b), the adopted leg circuit based on the used averaged model is presented. In this developed model, the leg switches are replaced by a controlled voltage source $V_{1}$ in series with a controlled current source $\mathrm{I}_{1}$ given by

$$
\mathrm{V}_{1}=\left\langle\mathrm{U}_{\mathrm{as}}\right\rangle \text { and } \mathrm{I}_{1}=\left\langle\mathrm{i}_{\mathrm{e} 2}\right\rangle
$$

With $\left\langle U_{a s}\right\rangle$ and $\left\langle i_{e 2}\right\rangle$ are the time averaged values of the instantaneous terminal waveforms of $\mathrm{U}_{\mathrm{as}}(\mathrm{t})$ and $\mathrm{i}_{\mathrm{e} 2}(\mathrm{t})$ respectively over one cycle Ts (switching period of the controlled switches). 


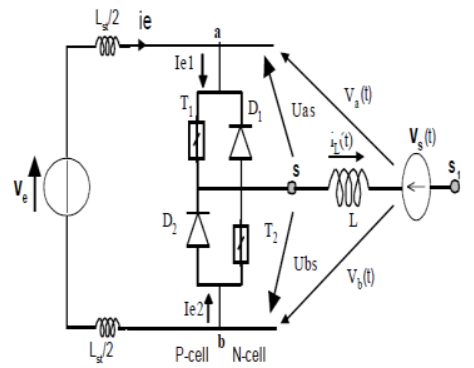

(a)

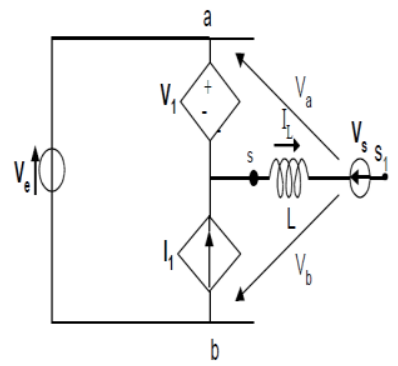

(b)
Figure 4. (a). The PWM-switch, (b). The corresponding averaged model

Figure 5 shows the adopted switching waveforms of the active switch $\left(\mathrm{U}_{\mathrm{as}}(\mathrm{t}), \mathrm{i}_{\mathrm{el}}(\mathrm{t})\right)$ and the passive switch $\left(\mathrm{U}_{\mathrm{bs}}(\mathrm{t})\right.$, $\mathrm{i}_{\mathrm{e} 2}(\mathrm{t})$ ) during the switching period $\mathrm{T}_{\mathrm{s}}$. The driving signals $\mathrm{e}_{\mathrm{g} 1}$ and $\mathrm{e}_{\mathrm{g} 2}$ are the control signals of $\mathrm{T}_{1}$ and $\mathrm{T}_{2}$ respectively.

The power losses of semiconductors $\left(\mathrm{P}_{\text {switch }}\right.$ and $\left.\mathrm{P}_{\text {diode }}\right)$ are estimated using this analytical representation of the switching characteristics which including both conduction and switching losses, and considering the various conduction and switching times.

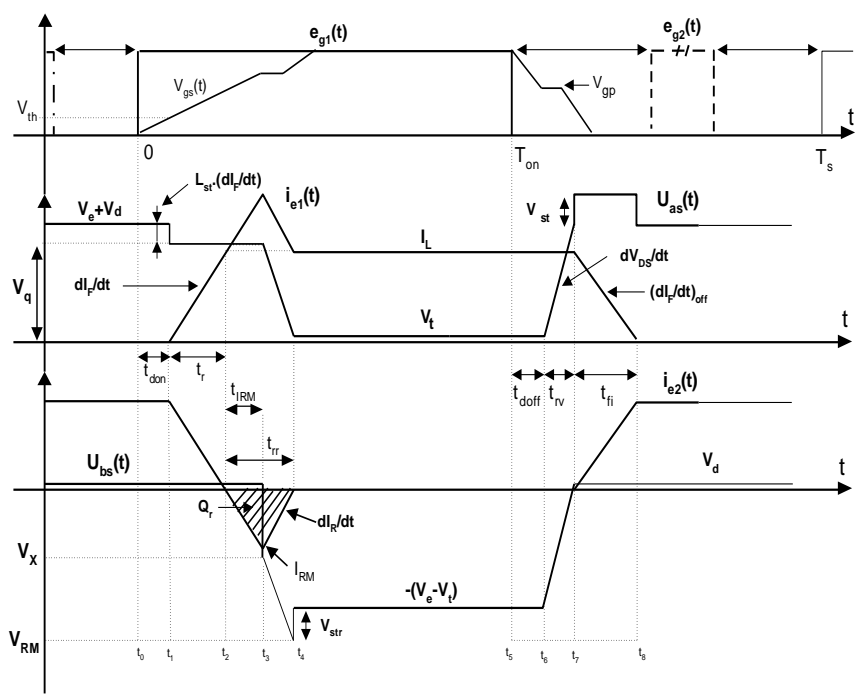

Figure 5. Adopted switching characteristics for the switch and the diode components in the PWM-switch cell,

Different static and dynamic power devices parameters can be deduced from their data sheets or by experiments.

The developed average model allows computing all the dissipated power in the semiconductor devices and then deducing the different converters efficiencies [22]. Time domain simulations will be more rapid for the whole PV chain system.
The efficiencies of the different converters used in the different chains were evaluated by mean of refined simulations. The evolutions of these efficiencies as a function of the transferred power $\eta(\mathrm{P})$ are shown in figure 6 . The used, controlled, devices in the converters are the $\mathrm{N}$-channel $\mathrm{SiC}$ power Mosfet's SCT3080KL. Internal anti-parallel diode of the Mosfet is used for reverse current in the switch.

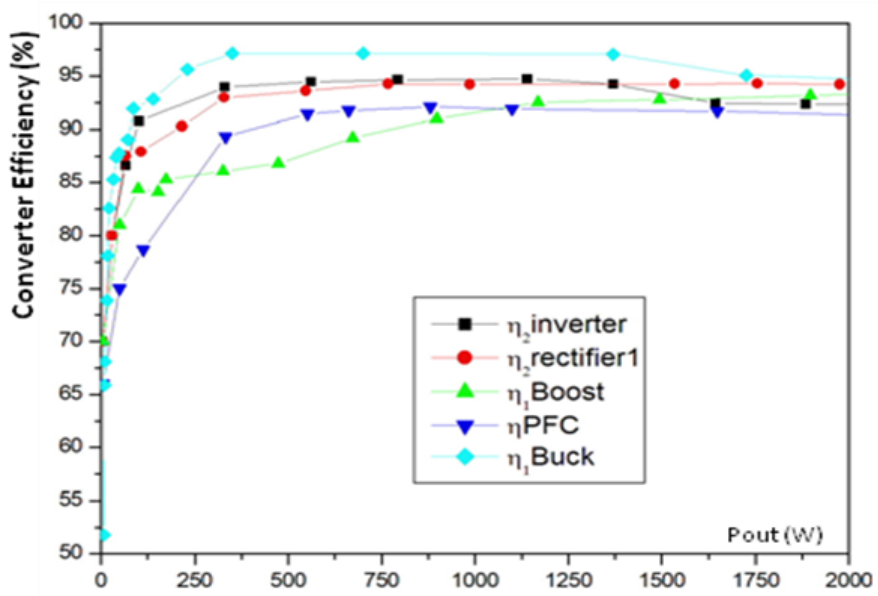

Figure 6. Different converters efficiency

We defined the saved energy, $\mathrm{W}_{\mathrm{i}}(\mathrm{i}=1,2,3)$, by a PV chain, the excess of energy injected in to the grid after satisfying the load need. It is the energy balance per month. We note that the chosen maximum power generated by the PV panel is $1500 \mathrm{~W}$ for a $25^{\circ} \mathrm{C}$ Temperature and $1000 \mathrm{~W} / \mathrm{m}^{2}$ Irradiance conditions.

\section{STUDY OF LVDC SOLUTIONS EFFICIENCIES}

Jeddah-KSA location ( $\left.21^{\circ} 32^{\prime} 34^{\prime \prime} \mathrm{N}, 39^{\circ} 10^{\prime} 22^{\prime \prime} \mathrm{E}\right)$ was chosen to perform energy efficiency performances of the different studied PV chains. Jeddah features an arid climate under Koppen's climate classification, with a tropical temperature range.

The following graphs in figure 7 shows the solar radiation during a typical day in each month for Jeddah city, which was monitored from the station of University King Abdul-Aziz. In the figure graphs typical days divided by seasons. A higher value of solar radiation in July and reaches nearly to more than $984 \mathrm{~W} / \mathrm{m}^{2}$. 


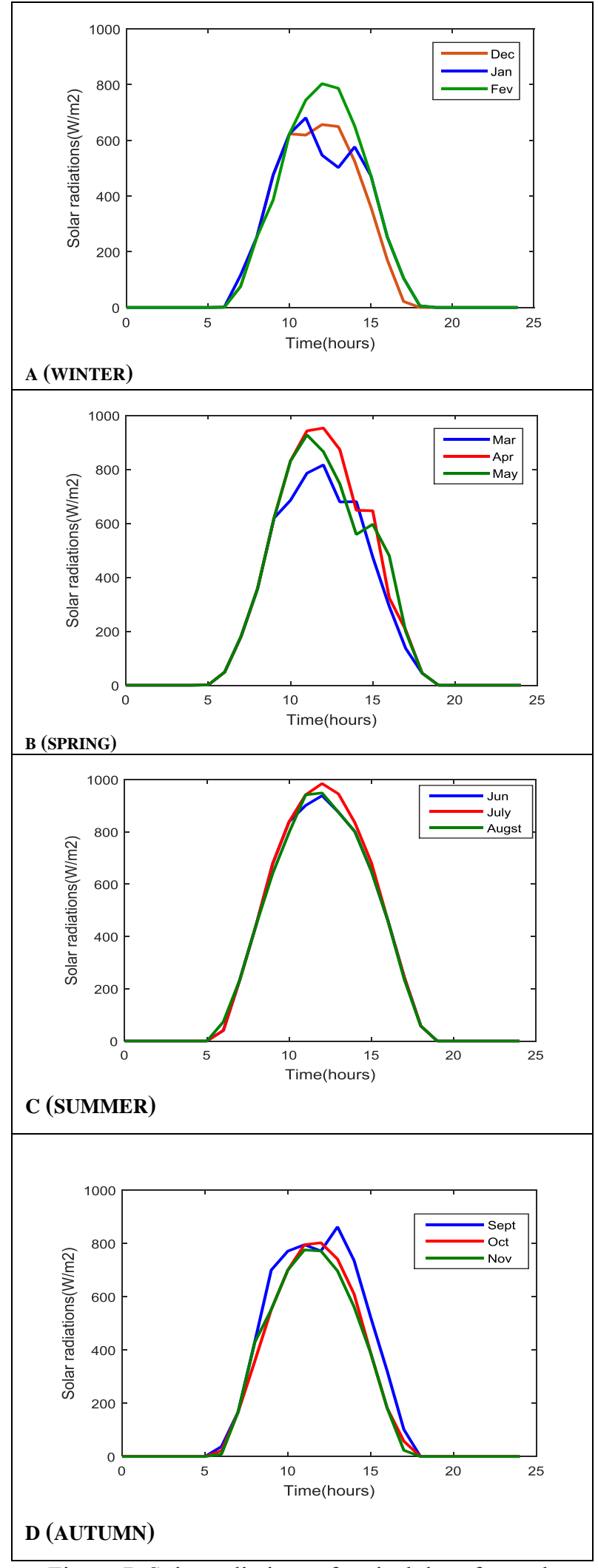

Figure 7. Solar radiations of typical days for each month and seasons
The generated power by the panels during a typical day of January in Jeddah is shown in figure 8 . The PV panels generated energy in this case is $6600 \mathrm{Wh} /$ day. The annual generated energy by the used PV panels $\mathrm{W}_{\mathrm{PV}}$ is equal to 3.006 MWh. This generated energy was calculated based on Irradiance, ambient Temperature and wind speed in Jeddah during each typical day/month in the year.

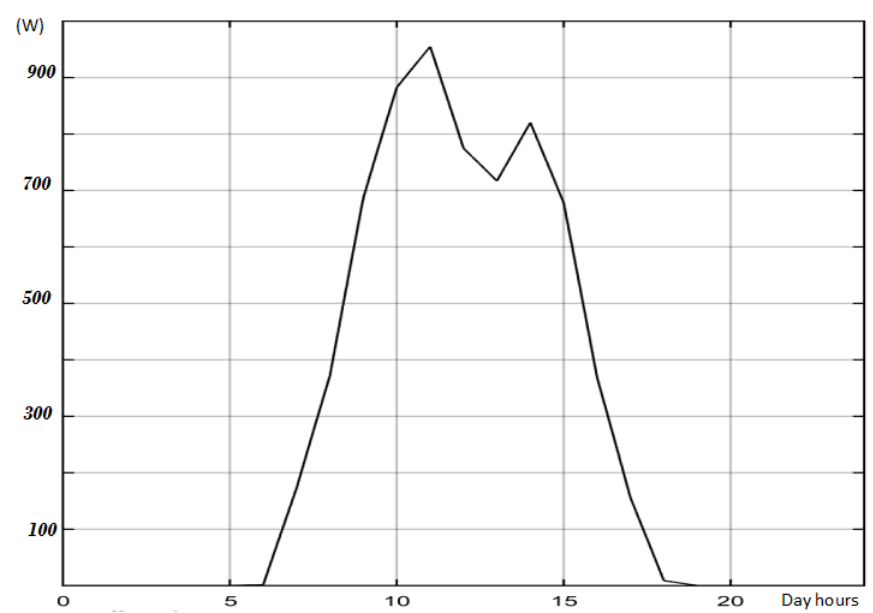

Figure 8. Generated power, by the used panels, during a typical day of January in Jeddah

We will describe the assess of the efficiency of the proposed LVDC PV chain solution (syst3) compared to the LVDC classic one (syst1) and the classical On-grid PV chain (syst2) using AC loads.

First, a load profile of an office was chosen in order to make comparison of the saved energy by the three studied PV chains. The profile of the load is shown in the following figure 9 and the daily consumed energy by one office is 2919 Wh. The annual consumed energy by one office is supposed to be about $\mathrm{W}_{\text {Load }}=1.068 \mathrm{MWh}$.

The considered office load is composed by, Desktop computer, Laptop, Laser printer, two Led lamps, small TV and a fan. Since the DC/DC converter $\left(\eta_{3}\right)$ is common for the three studied converters and located just before the load, it's effect was not taken into account in the study. 


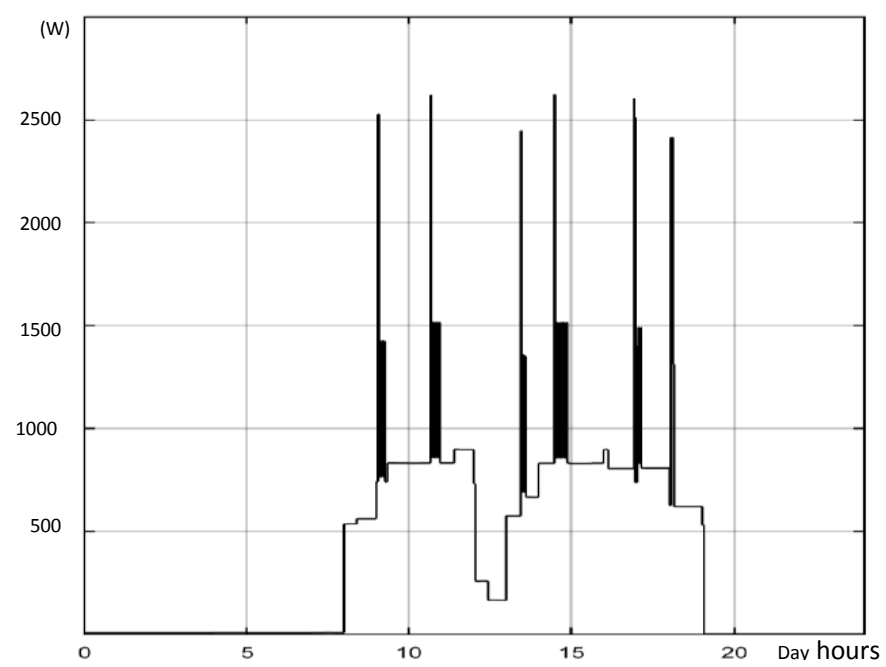

Figure 9. The assumed daily office load consumption (by 1 office)

The saved energy by the three models during each month of the year in Jeddah city is shown in figure 10. It is evident that the saved energy decreases with the increase of consumed power.

From figure 10, it's clear that the proposed new LVDC architecture (syst3) is the best one and register a higher saved energy $\left(\mathrm{W}_{3}=1.467 \mathrm{MWh} /\right.$ year when only one office load is considered) compared to the other chains $\left(\mathrm{W}_{2}=1.357\right.$ $\mathrm{MWh} /$ year and $\mathrm{W}_{1}=1.319 \mathrm{MWh} /$ year when only one office load is considered too). This is due to the localization of the load connection, in the LVDC chain, close to the PV panels which is the main introduced modification in the proposed LVDC system regarding to classical LVDC ones. We note that when the saved energy $W_{i}$ is negative this mean that the consumed energy is higher than generated one and so, this energy is transferred from the grid to the PV system.

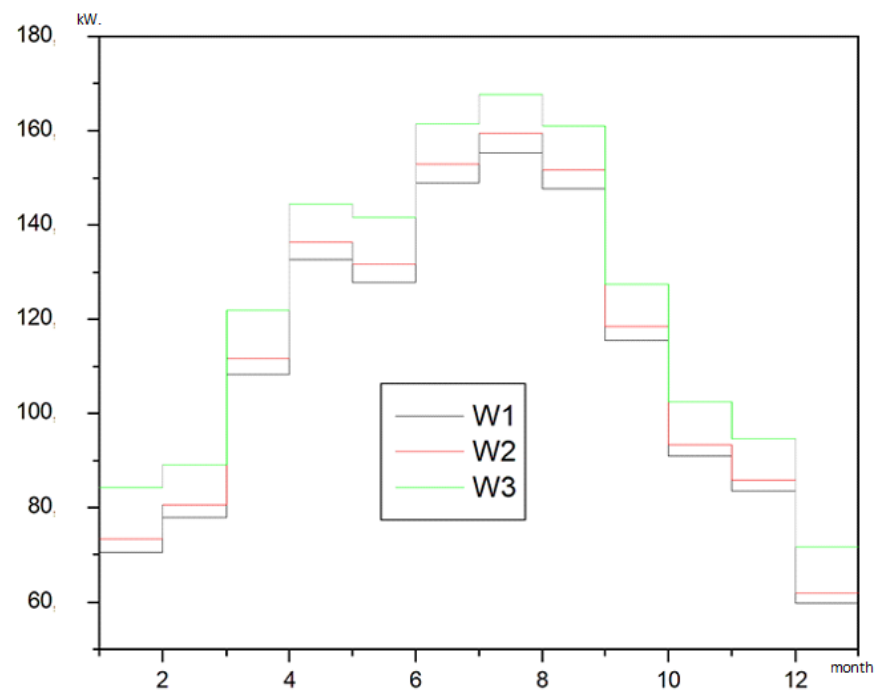

(a)

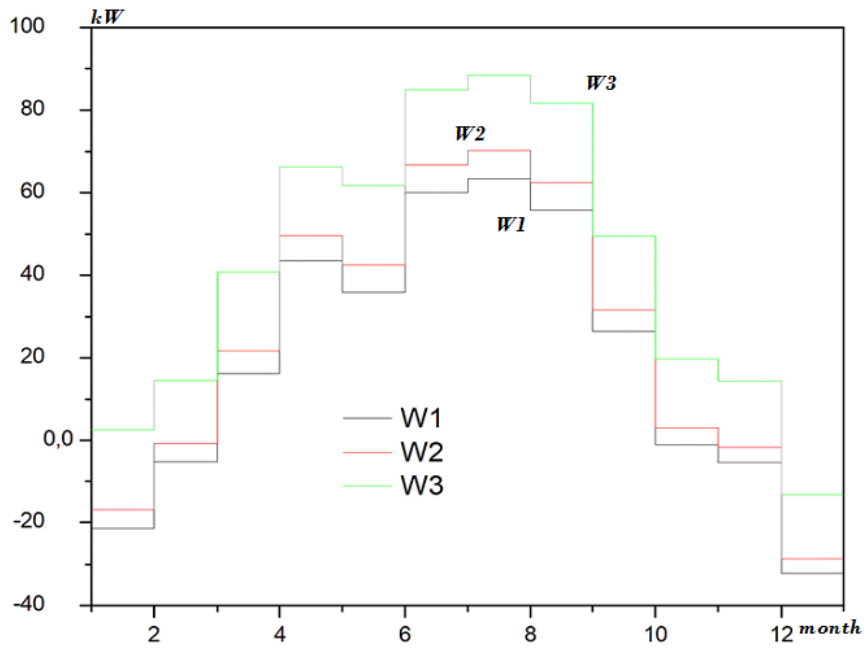

(b)

Figure 10. Annual saved energy by the three PV chains models (classical On-grid (syst1), Classical LVDC (syst2), proposed LVDC (syst3)) for each month of the year in Jeddah city (for

(a):one office and (b): two offices load).

We varied the consumed Energy by the load and we registered the saved energy by each PV system. It was remarked a very interesting propriety of the PV LVDC systems related to the increase of their efficiency compared to classical PV chain.

In fact, We define the Relative Saved Energy $\left(\mathrm{RSE}_{\mathrm{j}} \%\right.$ ) of the PV LVDC chain (syst j) to the classical PV chain (syst1), the ratio of the excess of saved energy of the given LVDC chain $\left(\mathrm{W}_{2}\right.$ or $\left.\mathrm{W}_{3}\right)$ regarding to the classical PV system $\left(\mathrm{W}_{1}\right)$ by the value of the annual generated $\mathrm{PV}$ energy $\mathrm{W}_{\mathrm{PV}}$.

The defined PV system $\mathrm{RSE}_{\mathrm{j}}$ regarding to the classical PV chain is given by the following equation.

$$
\operatorname{RSE}_{\mathrm{j}}(\%)=\left(\mathrm{W}_{\mathrm{j}}-\mathrm{W}_{1}\right) / \mathrm{W}_{\mathrm{PV}} \times 100 \% \text { with } \mathrm{j}=2,3
$$

If the defined efficiency is negative this mean that classical On-Grid PV chain (syst1) using AC sockets for load supplies is better (in term of energy saving) than the PV LVDC supplies concept. 


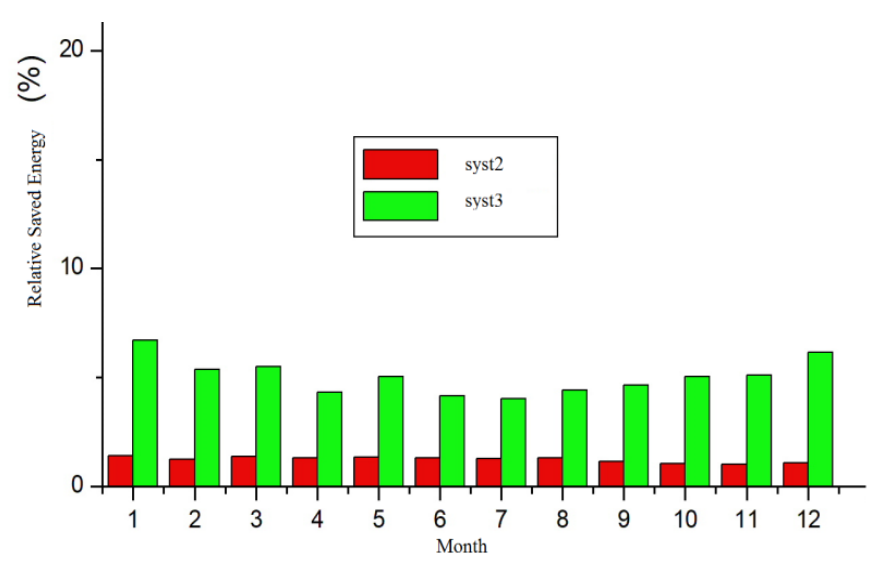

Figure11. Relative Saved Energy for the two systems, 2 and 3 in each month (number of offices $=1$ )

Figure11 shows the relative saved energy for the two systems 2 and 3 in January (office $=1$ ). The figure 11 illustrates that the relative saved energy for the systems 3 is more important than the system 2 .

The waveforms giving the evolution of the LVDC chains RSE as function of load energy by PV energy rate $\left(\frac{W_{\text {Load }}}{W_{P V}}\right)$ is shown in figure 12. Two main observations can be highlighted when interpreting these waveforms:

First, it is clear that the RSE of the proposed LVDC chain (syst3) is higher than the classical LVDC one (syst2) till a high load consumed energy (2.5 time the PV generated energy in our case).

Second, an optimum of these waveforms are registered when the consumed energy is around the generated energy by the PV panels. The maximum yearly RSE of the new LVDC architecture (syst3) is about $12 \%$ while the one registered by the classical LVDC chain (syst2) is about $2.3 \%$.

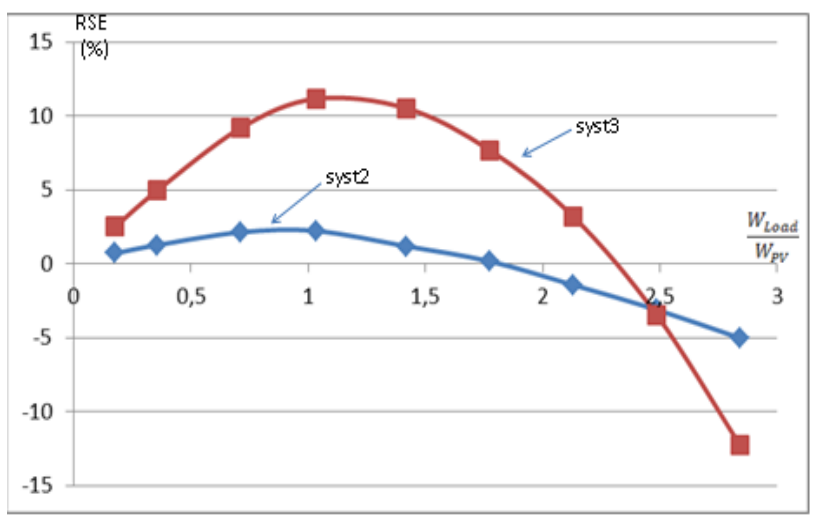

Figure 12. Yearly Relative Saved Energy of classical LVDC system2 and proposed LVDC system3

From figure 12, we can remark that when the load power consumption increases, the RES become negative, this mean that the classical PV chain, using AC supply to feed loads, is better solution than the LVDC one in this case. We can remark also, that for a high load consumption, the LVDC chain (syst2) become more interesting than the proposed LVDC chain (syst3).

In addition, the use of system 3 allow the increase of the load energy consumption range (more than two time the generated $\mathrm{PV}$ energy) where the LVDC supply concept efficiency is higher than other systems.

All the obtained results show that the use of the LVDC chain supply concept is very interesting and the use of DC loads instead of AC loads when a PV power is generated locally increase the PV system efficiency.

The installed PV power in the building should be well sized regarding to the consumed power in order to register a high system RSE. In this case an LVDC system RSE can be higher than $10 \%$ compared to the classical AC supply in PV systems.

\section{CONCLUSION}

In this paper we proposed a new architecture of a Low Voltage Direct Current (LVDC) supply concept. The proposed on grid PV chain system, involving DC loads, can replace the classical on-Grid PV systems using AC plugs to supply electric AC loads. To evaluate the efficiency of some different PV chains, non-ideal averaged models of the different converters, have been used. These models are accurate and suitable to complex systems study. The Energy efficiency of the different PV chains were estimated by mean of simulations. The evaluation of the efficiency of the proposed new LVDC architecture compared to the classical one was performed in the case of building offices in Jeddah. The superiority of the proposed LVDC PV chain was shown, it depends on the consumed load energy to generated PV Energy ratio.

Acknowledgements: This paper contains the results and funding of a research projects funded by King Abdulaziz City for Science and Technology (KACST) Grant no. 14ENE2677-10.

\section{REFERENCES}

[1] Leonardo Trigueiro dos Santos, Manuela Sechilariu and Fabrice Locment," Optimized Load Shedding Approach for Grid-Connected DC Microgrid Systems under Realistic Constraints," Buildings, pp1-15, 2016.

[2] International Electrotechnical Commission (IEC) Report on LVDC Electricity for the 21st Century, 2017.

[3] D. Kumar et al," DC Microgrid Technology: System Architectures, AC Grid Interfaces, Grounding Schemes, Power Quality, Communication Networks, Applications, 
and Standardizations Aspects," IEEE Access.,vol, 5,pp. 12230-12256, 2017.

[4] A. Ghareeb, A. Mohamed, and O. Mohammed, "DC microgrids and distribution systems: An overview," in Power and Energy Society General Meeting (PES), 2013 IEEE, Jul 2013, pp. 1-5.

[5] Ahmed T. Elsayeda, Ahmed A. Mohamedb, Osama A. Mohammeda," DC microgrids and distribution systems: An overview", Electric Power Systems Research 119 (2015) 407-417.

[6] J Pellis. The DC low-voltage house. Graduation project, Eindhoven University of Technology,1997.

[7] R. H. Lasseter, "Microgrids," in Power Engineering Society Winter Meeting, 2002. IEEE, 2002, vol. 1, pp. 305-308.

[8] Jifei Du, Trillion Q. Zheng, Yian Yan, Hongyan Zhao, Yangbin Zeng and Hong Li," Insulation Monitoring Method for DC Systems with Ground Capacitance in Electric Vehicles », Appl. Sci. 2019, 9, 2607, pp.1-15.

[9] Gyuyoung Yoon, Kyoko Sugiyama, Saya Yoshioka and Shinji Sakai," Energy Efficiency and Cost Performance of Direct-Current Power Supply Systems in Residential Buildings by 2030s and 2050s", E3S Web of Conferences 111 CLIMA 2019.

[10] Tomm Aldridge." Direct 400Vdc for Energy Efficient Data Centers Direct 400Vdc Facility Vision”. Technical Report April, Intel Corporate Technology Group, 2009.

[11]Brian Fortenbery. "DC Power Standards", Technical Report March, Electric Power Research Institute, 2011.

[12] AlLee, G., and Tschudi, W., "Edison redux: 380 vdc brings reliability and efficiency to sustainable data centers," IEEE Power Energy Mag., Vol. 10, No. 6, pp. 50-59, November2012.

[13] Weiss, R., Ott, L., and Boeke, U., "Energy efficient low voltage DC-grids for commercial buildings," IEEE First International Conference on DC Microgrids (ICDCM). IEEE, June 2015, pp. 154-158.

[14] Thi Thuong Huyen , Hamed Yahoui, Hoang Giang Vu , Nicolas Siauve and Hervé Morel," A Control Strategy of DC Building Microgrid Connected to the Neighborhood and AC Power Network", Buildings 2017, 7, 42,pp.1-12.

[15] V. Vossos et al." Energy savings from direct-DC in U.S. residential buildings", Energy and Buildings 68 (2014), pp.223-23.1

[16] Paul Savage, Robert R. Nordhaus, and Sean P. Jamieson. DCMicrogrids: "Benefits and Barriers".Technical report, Yale School of Forestry and Environmental Studies, 2010.

[17] Patterson, B. T," Dc, come home". IEEE power \& energy magazine (2012, November/December), pp.60-69.

[18] Salonen, P., Kaipia, T., Nuutinen, P., Peltoniemi, P., and Partanen, J., "An LVDC distribution system concept,"
Nordic Workshop on Power and Industrial Electronics (NORPIE'08), 2008.

[19] Werth, A., Kitamura, N., and Tanaka, K., "Conceptual Study for Open Energy Systems: Distributed Energy Network Using Interconnected DC Nanogrids," IEEE Trans. Smart Grid, Vol. 6, No. 4, pp. 1, 2015.

[20] Rodriguez-Diaz, E., Chen, F., Vasquez, J. C., Guerrero, J. M., Burgos, R., and Boroyevich, D., "Voltage-Level Selection of Future Two-Level LVdc Distribution Grids: A Compromise Between Grid Compatibiliy, Safety, and Efficiency," IEEE Electrif. Mag., Vol. 4, No. 2, pp. 2028, June 2016.

[21]A. AMMOUS and H. Morel, "LVDC: An Efficient Energy Solution for On-Grid Photovoltaic Applications" Smart Grid and Renewable Energy, 2014, Vol. 5, No. 4, pp. 63-76.

[22] A. AMMOUS et al « Developing a PWM-switch model including Semiconductor Device Non-linéarities » IEEE Transactions on Power Electronics, Vol.18, No.5 ,September 2003.

\section{Creative Commons Attribution License 4.0 (Attribution 4.0 International, CC BY 4.0)}

This article is published under the terms of the Creative Commons Attribution License 4.0 https://creativecommons.org/licenses/by/4.0/deed.en_US 